\title{
Knowledge, Attitude, and Practice of Contraception Methods Among Female Undergraduates in Dodoma, Tanzania
}

\author{
Waheeda Shokat K. Kara ${ }^{1}$, Magreth Benedicto ${ }^{2}$, Jing Mao ${ }^{3}$ \\ 1. Nursing Psychiatry, Tongji Medical College, Huazhong University of Science and Technology, Wuhan, CHN 2. \\ Psychology, St. John's University of Tanzania, Dodoma, TZA 3. Nursing, Tongji Medical College, Huazhong University \\ of Sciences and Technology, Wuhan, CHN
}

$\square$ Corresponding author: Waheeda Shokat K. Kara, wskkara@gmail.com Disclosures can be found in Additional Information at the end of the article

Received 03/21/2019

Review began 03/26/2019 Review ended 03/28/2019

Published 04/02/2019

(๑) Copyright 2019

Kara et al. This is an open access article distributed under the terms of the Creative Commons Attribution License CC-BY 3.0., which permits unrestricted use, distribution, and reproduction in any medium, provided the original author and source are credited.

\section{Abstract \\ Introduction}

Contraception is regarded as an important preventive measure of unintended pregnancies and sexually transmitted diseases, including human immunodeficiency virus infection and acquired immune deficiency syndrome (HIV/AIDS), among youths. This study aimed to assess the knowledge, attitude, and practice of contraception among female undergraduates in Dodoma, Tanzania.

\section{Methodology}

A cross-sectional study was conducted among 347 female undergraduates of St John's University, Dodoma. Descriptive statistics were used for data analysis. Statistical analysis was done using Epi-Info version 7.2.2.6 (Centers for Disease Control and Prevention, Atlanta, Georgia. A p-value of less than 0.05 was considered statistically significant.

\section{Results}

The mean $\left({ }^{ \pm} \mathrm{SD}\right)$ age of participants was $27.4( \pm 5.7)$. The majority (96\%) of the participants were aware of contraception. Awareness of contraception was significantly associated with the age $(\mathrm{p}<0.0001)$, marital status ( $p<0.00001)$, and religion of the participating students $(\mathrm{p}=0.02)$. Slightly less than half $(47.4 \%)$ of the students reported having ever used at least one type of contraception while feeling embarrassed to buy or ask for contraception (64.6\%) and differing religious beliefs (32.3\%) were among the reasons reported by students for not using contraception.

\section{Conclusion}

Despite the relatively low utilization of contraception, the majority of the participants had knowledge of contraception. This calls for efforts to advocate the effective utilization of reproductive and sexual health services among youths.

Categories: HIV/AIDS, Public Health, Epidemiology/Public Health

Keywords: knowledge, attitude, practice, contraception, female university students

\section{Introduction}

Almost 20\% of the Tanzanian population is between 15 and 24 years of age [1]. This group constitutes the majority of youths who join universities in Tanzania. Although the group is the most sexually active, girls in the group are faced with more challenges in accessing contraceptives than are married women due to the stigma attached to their sexual activities before marriage. This poses the risk of unwanted and teen pregnancies and unsafe abortions [2]. The latter is a significant public health concern in many developing countries, with the most recent publication showing global annual incidence estimates that suggest that 25.1 million women had undergone unsafe abortions between 2010 and 2014 [3].

Despite being freely available at health facilities throughout the country, the utilization of contraception among students, especially females, remains low, with increased rates of unplanned pregnancies being reported [4]. Previous reports in Tanzania have shown the utilization of contraception among secondary school students to be between $11.8 \%$ and $40.0 \%$ despite students exhibiting a relatively high knowledge of contraception [5-8]. In the general population, the contraception uptake rate has been reported to vary from $19.0 \%$ to $34.4 \%[4,8]$.

How to cite this article

Kara W K, Benedicto M, Mao J (April 02, 2019) Knowledge, Attitude, and Practice of Contraception Methods Among Female Undergraduates in Dodoma, Tanzania. Cureus 11(4): e4362. DOI 10.7759 /cureus. 4362 
The correct use of contraception can prevent unintended pregnancies, unsafe abortions, and sexually transmitted infections, including HIV [9]. Unwanted pregnancies among students of higher learning institutions create a major public health problem, particularly in developing countries, and may jeopardize students' learning and potential careers. Globally, several studies have reported on the knowledge, attitude, and practice toward the use of contraception among various groups of students [10-14] but little is known about the current knowledge, attitude, and practice toward the use of contraception among young females in this study setting.

Most previous studies have concentrated mainly on primary and secondary school girls, and only a few have addressed the problem of the low utilization of contraception among university students. Further, to the best of our knowledge, no study has been conducted in this study area to assess the knowledge, attitude, and practice of methods of contraception among female university students. This study, therefore, aimed to assess the knowledge, attitude, and practice of contraception methods among female undergraduate students in Dodoma, Tanzania.

\section{Materials And Methods \\ Study design, setting, and population}

This was a cross-sectional descriptive study conducted among undergraduate university students in Dodoma city, Tanzania. The study population consisted of female undergraduate students at the main campus of St John's University of Tanzania. This is one of the largest universities in the city and is located about five km from the city center. The university offers both undergraduate and postgraduate programs to about 5000 students.

\section{Sampling and sample size}

The study site was randomly selected from a list of universities located in Dodoma. A sample size of 347 students was calculated using the Kish, Leslie formula [15] based on the previous prevalence of users of contraception (34.4\%) reported in a study conducted at another university in eastern Tanzania [5], with a $95 \%$ confidence interval and $\mathrm{a} \pm 5 \%$ degree of precision.

\section{Inclusion and exclusion criteria}

The study included all first to fourth-year, full-time, registered, female undergraduate students of all age groups. Another inclusion criterion was a willingness to participate in the study. Exclusion criteria included an unwillingness to participate and being a part-time or distance learning student.

\section{Data collection}

Students who consented to participate were interviewed using pre-tested, self-administered structured questionnaires. The collected information included socio-demographic characteristics, knowledge of students on modern contraceptives, students' attitude toward the use of modern contraceptives, and students' practices toward the use of contraception. Dependent variables included knowledge, attitude, and practice of contraception, whereas independent variables were age, year of study, marital status, program of study, and source of information about contraception.

\section{Data analysis}

Statistical analyses were done using Epi-Info version 7.2.2.6 (Centers for Disease Control and Prevention, Atlanta, USA). Continuous data were expressed as means \pm standard deviation (SD) and categorical data as percentages. The chi-square tests were used to determine the association between categorical variables. A pvalue of less than 0.05 was considered statistically significant.

\section{Ethical considerations}

Informed written consent was obtained from each participant. The study protocol was collaboratively approved by the Institutional Review Board of Tongji Medical College, Huazhong University of Science and Technology, and the University Research Internal Ethical Committee of St John's University of Tanzania.

\section{Results}

\section{Socio-demographic characteristics of respondents}

A total of 347 students were recruited in the study, with a response rate of $100 \%$. The mean \pm SD age of participants was $27.4 \pm 5.7$ years. Approximately $68.0 \%$ of the participants were aged between 21 and 30 years, $80.4 \%$ were single, and $40.6 \%$ were first-year students. Table 1 summarizes the socio-demographic characteristics of the study participants. 


\section{Cureus}

\section{Categorical variables}

Age

$15-20$

21-30

$31-40$

41-50

Marital status

Single 279(80.4)

Married 62(17.8)

Cohabiting

Divorced

Religion

Christian

Muslim

Others

FANAS

123(35.4)

83(24.0)

\section{TABLE 1: Socio-demographic characteristics of the study participants, $n=347$}

Abbreviations: FOCB, Faculty of Commerce and Business Studies; FAHE, Faculty of Humanities and Education; FANAS, Faculty of Natural and Applied Sciences

\section{Knowledge of contraceptive methods}

The majority of the participants, 333 (96.0\%), were aware of contraception. Knowledge of methods of contraception was assessed by scoring the responses of participants on the various methods of contraceptives they know. If a participant mentioned none or only one correct method of contraception, she was regarded as having poor knowledge, whereas good knowledge was when a participant mentioned two or more correct methods. Of the participants who were aware of contraception, $83.5 \%$ mentioned oral contraceptives as one of the methods of contraception and $45.7 \%$ mentioned mass media as their main source of information regarding contraception. Of those who were aware of contraception, $92.2 \%$ stated that contraception prevents unwanted pregnancies. Table 2 shows the knowledge of students about contraception. 


\section{Cureus}

Categorical variables

Number, n(\%)

Awareness on contraception $(n=347)$

Aware

$333(96.0)$

Not aware

14(4.0)

Knowledge of methods of contraception $(n=333)$

Good

$326(97.9)$

Poor

Known methods of contraception $(n=333)$

Pills

Condoms

Injectable contraceptives

$199(59.8)$

Natural methods

Implants

Loop

Tubal ligation

Vasectomy

Known reasons for using contraception $(n=333)$

Prevention of unwanted pregnancy

Prevention of sexually transmitted infections

Means of family planning

Sources of information about contraception $(n=333)$

Mass media

152(45.7)

Friends

76(22.8)

Health care workers

School teachers

Parents

TABLE 2: Knowledge of students regarding contraception

We used the chi-square test to determine the association between the awareness of contraception and sociodemographic characteristics of the study participants. We found a significant association between the awareness of contraception, the age of participants $(p<0.0001)$, marital status $(p<0.00001)$, and the religion of the students $(\mathrm{p}=0.02)$. Table 3 shows the association between the awareness of students of contraception and their socio-demographic characteristics. 


\section{Cureus}

\begin{tabular}{|c|c|c|c|}
\hline Categorical variables & Aware, n (\%) & Not aware, $n(\%)$ & p-value \\
\hline \multicolumn{4}{|l|}{ Age } \\
\hline $15-20$ & 21(84.0) & $4(16.0)$ & \multirow{4}{*}{$<0.0001$} \\
\hline $21-30$ & 232(98.7) & $3(1.3)$ & \\
\hline $31-40$ & 72(93.5) & $5(6.5)$ & \\
\hline $41-50$ & $8(80.0)$ & $2(20.0)$ & \\
\hline \multicolumn{3}{|l|}{ Marital status } & \multirow{5}{*}{$<0.00001$} \\
\hline Single & $270(96.8)$ & $9(3.2)$ & \\
\hline Married & 61(98.4) & $1(1.6)$ & \\
\hline Cohabiting & $1(50.0)$ & $1(50.0)$ & \\
\hline Divorced & $1(25.0)$ & $3(75.0)$ & \\
\hline \multicolumn{3}{|l|}{ Religion } & \multirow{4}{*}{0.02} \\
\hline Christian & 204(97.1) & $6(2.9)$ & \\
\hline Muslim & 127(94.8) & $7(5.2)$ & \\
\hline Others & $2(66.7)$ & $1(33.3)$ & \\
\hline \multicolumn{3}{|l|}{ Faculty } & \multirow{4}{*}{0.36} \\
\hline FOCB & $129(97.7)$ & $3(2.3)$ & \\
\hline FAHE & 109(95.6) & $5(4.4)$ & \\
\hline FANAS & $95(94.1)$ & $6(5.9)$ & \\
\hline \multicolumn{3}{|l|}{ Year of study } & \multirow{4}{*}{0.14} \\
\hline First year & $132(93.6)$ & $9(6.4)$ & \\
\hline Second year & 121(98.4) & $2(1.6)$ & \\
\hline Third year & $80(98.8)$ & $3(1.2)$ & \\
\hline
\end{tabular}

\section{TABLE 3: Association between awareness of contraception and socio-demographic}

characteristics, $n=347$

Abbreviations: FOCB, Faculty of Commerce and Business Studies; FAHE, Faculty of Humanities and Education; FANAS, Faculty of Natural and Applied Sciences

\section{Attitudes of participants toward contraception}

Table 4 provides a detail of the attitudes of students toward the use of contraception methods. About $65.8 \%$ of the participants responded that contraceptives tend to reduce sex drive while $32.7 \%$ of the participants said condoms can slip off during sexual intercourse. About half (50.8\%) of the students reported that it was more desirable to use contraception than to have an abortion. 


\section{Cureus}
Attitudes toward contraception
Number, $\mathbf{n}(\%)$
Contraception is beneficial
271(81.4)
Contraception reduces sex drive
219(65.8)
Condoms can slip off during sexual intercourse
109(32.7)
Contraception better than abortion
169(50.8)
Will use contraception in future
41(12.3)

TABLE 4: Attitudes of students toward the use of contraception, $n=333$

\section{Practice of contraception methods}

About $47.4 \%$ of the students who had knowledge of contraception had never used any method of contraception in their lifetime. Among the reasons for not using condoms were: contraception is against religious beliefs (32.3\%) and a feeling of embarrassment while buying or asking for contraception at the facilities (64.6\%). Oral contraceptives were the most commonly used method of contraception (54.9\%) while pharmacies were the most common source of contraception (53.1\%). Table 5 shows the practices of study participants toward the use of contraception.

\section{Variables}

Ever used contraception $(n=333)$

Yes

No

Reasons for using contraception $(n=175)$

To prevent unwanted pregnancy

To prevent sexually transmitted infections

For family planning

Others

Reasons for not using contraception $(n=158)$

Against religious beliefs

Reduces sexual pleasure

Causes cancer

Causes weight gain

Not readily available

My partner disapproves

I fear its side effects

Lacking enough knowledge on how to use

Embarrassed to buylask for them

Used contraceptive methods $(n=175)$

Pills

Condoms

Injectable contraceptives 


\section{Cureus}

Norplants

Other methods

Places to get contraception $(n=175)$

Pharmacy

Nearby government health care facilities

Private health facilities

Other facilities/sources

Ever used emergency contraception $(n=183)$

Yes

No

Reasons for not using emergency contraception $(n=114)$

No knowledge of emergency contraception

On other contraception

Fear of side effects

17(14.9)

TABLE 5: Practices of students toward the use of contraception

We also assessed the awareness, practices, and attitudes of students toward the use of emergency contraception. Of the 333 students who were aware of contraception, 183 (55.0\%) were aware of emergency contraception and only 69 (37.7\%) had used emergency contraception. Lack of adequate knowledge on how to use emergency contraception (63.2\%) and fear of side effects (14.9\%) were among the reasons for not using emergency contraception (Table 5).

\section{Discussion}

This study was aimed to assess the knowledge, attitude, and practice of contraception methods among female undergraduate students in Dodoma city. We recruited female students of reproductive age between 15 and 49 years with the mean $( \pm$ SD) age of $27.4( \pm 5.7)$. This was an appropriate age limit because the use of contraception is mainly age-dependent. We found the majority (80.4\%) of our participants were not married, a finding similar to that from a study among university students in Uganda (87.5\%) [16] and another in Kilimanjaro, Tanzania [8], where $76.6 \%$ of the participants were also single.

The findings from this study imply being aware of contraception was significantly associated with the age, marital status, and religion of the participants. The reported association is not uncommon, as the marital status and religion of an individual have been shown to influence the awareness and use of contraception among believers [17-19]. The large proportion of participants in this study with knowledge of the methods of contraception is consistent with findings reported elsewhere $[5,8,17-18]$. It is possible that this high level of knowledge is ascribed to the mass campaign on contraception previously carried out throughout the country.

The majority of participants knew various methods of contraception, with each participant mentioning at least one method. They mostly mentioned condoms (88.0\%) and oral contraceptives (83.5\%) as the frequently known methods of contraception. However, the overall use of contraceptives was generally low, with only slightly more than half of the students reporting using one or more methods of contraception. Despite condoms and oral contraceptives being the most mentioned methods, their use was relatively low. This finding is consistent with findings previously reported elsewhere $[8,10,16,19-20]$.

The source of information on contraception is key to relaying the correct information to students, particularly the young ones. Our findings show that the most common sources of information were mass media, friends, and health-care workers. Similar findings were reported in studies in Kilimanjaro [8] and Botswana [21] but different from studies among similar groups in India [10], where media was the commonest source of information, and in Nigeria [22], where health care facilities were the most common 
sources of information. Having a reliable source of information such as mass media and health care facilities/workers is likely to provide youths with more correct and accurate information than friends/relatives; it is thus justifiable to direct efforts toward disseminating information through reliable sources.

Participants showed mixed attitudes toward using contraceptives. Our findings show that the majority of students perceived contraception to be beneficial while a small proportion of students promised to use contraception in the future. On the contrary, about two-thirds agreed that contraception tends to reduce sex drive, with one-third saying condoms can slip off during sexual intercourse. A study in Columbia [23], which aimed to address the impact of oral contraception on libido, observed that most women in the 17 reviewed studies reported an increase in sexual drive when using oral contraceptives. A study in Kilimanjaro [8] reported negative attitudes toward the use of contraception among students because of poor accessibility while participants in a study in Nigeria [24] perceived contraception as a cause of infertility.

Oral contraceptives and condoms were the most preferred methods of contraception among our participants. Our findings were similar to those reported in studies elsewhere [5,7,25]. We further observed that most students would rather prefer to procure contraception from local pharmacies than from health-care facilities due to the long waiting hours associated with other facilities' procedures. This is in line with findings reported in studies elsewhere [7-8]. This practice may imply a lack of sexual and reproductive health services customized to accommodate youths' needs.

Being a more sexually active group, it is not surprising that participants in this study group stated the prevention of sexually transmitted infections as the main reasons for using contraception. The reported reasons are similar to those reported in studies in Ghana [20] and Kilimanjaro [8]. Conversely, a fear of being embarrassed during purchasing and differing religious beliefs were the main reasons for not using contraception. In two studies in Uganda $[16,19]$ religious beliefs were concluded to be key determinants of poor uptake of contraceptives. In this study, one in three non-users claims they do so because their religions condemn the use of contraception. The findings call for necessary measures to address the matter.

About one in three students in this study acknowledged using emergency contraceptives. Lack of knowledge of emergency contraceptives was the main reason given by non-users. The findings are similar to those reported in Ethiopia [26] where about $40 \%$ of the students reported using emergency contraception, while in another study done among female undergraduates in Ahmadu Bello University in Nigeria [27], about a quarter of the respondents had used emergency contraception. In Tanzania, for example, individuals who are using emergency contraception are regarded as prostitutes by their peers, a perception that could hinder the use of emergency contraception among students. It is possible that misconception toward the use of emergency contraception between the communities could be the reason for the observed differences.

\section{Limitations}

This study has some limitations that need to be taken into account when interpreting the study results. First, the study population consisted of students from one university only. Therefore, we cannot generalize the findings from this study to all female undergraduate students in Tanzania. Second, students' practices and attitudes were self-reported; as a result, there might be an information bias because some information perceived to be sensitive by the students might not be reported. Third, without longitudinal data, it is not possible to construe a true cause and effect relationship between the knowledge and utilization of contraception. Therefore, we cannot draw a predictive conclusion based on these differences.

\section{Conclusions}

Female undergraduate students in this study are aware and have knowledge of contraception; however, their utilization of contraception and emergency contraception is relatively low. Establishing user-friendly reproductive and sexual health services will help improve student uptake of contraception methods.

\section{Additional Information Disclosures}

Human subjects: Consent was obtained by all participants in this study. Institutional Review Board of Tongji Medical College, Huazhong University of Science and Technology and University Research Internal Ethical Committee of St. John's University of Tanzania issued approval FM/12769. The study protocol was collaboratively approved by the Institutional Review Board of Tongji Medical College, Huazhong University of Science and Technology and the University Research Internal Ethical Committee of St. John's University of Tanzania. Animal subjects: All authors have confirmed that this study did not involve animal subjects or tissue. Conflicts of interest: In compliance with the ICMJE uniform disclosure form, all authors declare the following: Payment/services info: All authors have declared that no financial support was received from any organization for the submitted work. Financial relationships: All authors have declared that they have 
no financial relationships at present or within the previous three years with any organizations that might have an interest in the submitted work. Other relationships: All authors have declared that there are no other relationships or activities that could appear to have influenced the submitted work.

\section{Acknowledgements}

We are grateful for the work and support of Dr. Khamis Hassan Bakari of Tongji Medical College for the technical assistance and data analysis. We would also like to thank the students of St. John's University of Tanzania for their willingness to participate in this study.

\section{References}

1. Population and Housing Census 2012: population distribution by administrative areas . (2013). Accessed: November 22, 2018:

http://www.tzdpg.or.tz/fileadmin/documents/dpg_internal/dpg_working_groups_clusters/cluster_2/water/WSDP/Back

2. Calvert C, Owolabi OO, Yeung F, et al.: The magnitude and severity of abortion-related morbidity in settings with limited access to abortion services: a systematic review and meta-regression. BMJ Glob Health. 2018, 3:000692. 10.1136/bmjgh-2017-000692

3. Harper CC, Blanchard K, Grossman D, Henderson JT, Darney PD: Reducing maternal mortality due to elective abortion: potential impact of misoprostol in low-resource settings. Int J Gynaecol. Obstet, 2007:6669. Accessed: December 12, 2018: 10.1016/j.ijgo.2007.03.009

4. Tanzania. 2015-16 Demographic and Health Survey and Malaria Indicator Survey. Key findings . (2016). Accessed: December 12, 2018: https://www.dhsprogram.com/pubs/pdf/SR233/SR233.pdf.

5. Mung'ong'o SG, Mugoyela V, Kimaro B: Knowledge, attitude and practice on contraceptive use among secondary school students in Dar es Salaam, Tanzania. East and Central African Journal of Pharmaceutical Sciences. 2010, 13:43-49. Accessed: December 18, 2018: https://www.ajol.info/index.php/ecajps/article/view/107100.

6. Kagashe GAB, Honest G: Knowledge and use of contraceptives among secondary school girls in Dar es Salaam Tanzania. J Appl Pharm Sci. 2013, 3:66-68. 10.7324/JAPS.2013.30112

7. Somba MJ, Mbonile M, Obure J, Mahande MJ: Sexual behaviour contraceptive knowledge and use among female undergraduates' students of Muhimbili and Dar es Salaam Universities, Tanzania: a cross-sectional study. BMC Womens Health. 2014, 14:94. Accessed: November 11, 2018: 10.1186/1472-6874-14-94

8. Sweya MN, Msuya SE, Mahande MJ, Manongi R: Contraceptive knowledge, sexual behavior, and factors associated with contraceptive use among female undergraduate university students in Kilimanjaro region in Tanzania. Adolesc Health Med Ther. 2016, 3:109-115. Accessed: August 9, 2018: 10.2147/AHMT.S108531

9. Ong J, Temple-Smith M, Wong WCW, McNamee K, Fairley C: Contraception matters: indicators of poor usage of contraception in sexually active women attending family planning clinics in Victoria, Australia. BMC Public Health. 2012, 23:1108. Accessed: October 4, 2018: 10.1186/1471-2458-12-1108

10. Renjhen P, Kumar A, Pattanshetty S: A study on knowledge, attitude and practice of contraception among college students in Sikkim, India. J Turk Ger Gynecol Assoc. 2010, 11:78-81. Accessed: November 12, 2018 : 10.5152/jtgga.2010.03

11. Fantahun M, Chala F, Loha M: Knowledge, attitude and practice of family planning among senior high school students in North Gondar. Ethiop Med J. 1995, 33:21-29.

12. Mfono Z: Teenage contraceptive needs in urban South Africa: a case study . Int Fam Plan Perspect. 1998, 24:180-183.

13. Adinma JI, Okeke AO: Contraception awareness and practice amongst Nigerian tertiary school girls. West Afr J Med. 1995, 14:34-38.

14. McEwan B, Aukett R, Hills MD: High school students' attitudes towards and use of contraceptives . N Z Med J. 1988, 101:142-145.

15. Leslie Kish: Survey Sampling. John Wiley and Sons Inc, New York; 1965. 78-94.

16. Nsubuga H, Sekandi JN, Sempeera H, Makumbi FE: Contraceptive use, knowledge, attitude, perceptions and sexual behavior among female university students in Uganda: a cross-sectional survey. BMC Womens Health. 2016, 16:6. Accessed: November 13, 2018: 10.1186/s12905-016-0286-6

17. Ochako R, Mbondo M, Aloo S, Kaimenyi S, Thompson R, Temmerman M, Kays M: Barriers to modern contraceptive methods uptake among young women in Kenya: a qualitative study. BMC Public Health. 2015, 15:118. Accessed: November 8, 2018: 10.1186/s12889-015-1483-1

18. Agyei WK, Migadde M: Demographic and sociocultural factors influencing contraceptive use in Uganda . J Biosoc Sci. 1995, 27:47-60.

19. Mehra D, Agardh A, Petterson KO, Östergren P: Non-use of contraception: determinants among Ugandan university students. Glob Health Action. 2012, 5:18599. Accessed: January 5, 2018: 10.3402/gha.v5i0.18599

20. Hagan JE, Buxton C: Contraceptive knowledge, perceptions and use among adolescents in selected senior high schools in the central region of Ghana. J Sociol Res. 2012, 2:170-180. 10.5296/jsr.v3i2.2311

21. Hoque ME, Ntsipe T, Mokgatle-Nthabu M: Awareness and practices of contraceptive use among university students in Botswana. Sahara J. 2013, 10:83-88. Accessed: December 12, 2018: 10.1080/17290376.2013.869649

22. Oyedokun AO: Determinants of contraceptive usage: lessons from women in Osun State, Nigeria . Int J Humanit Soc Sci. 2007, 1:1-14

23. Davis AR, Castano PM: Oral contraceptives and libido in women. Annu Rev Sex Res. 2004, 15:297-320.

24. Orji EO, Adegbenro CA, Olalekan AW: Prevalence of sexual activity and family planning use among undergraduates in South West Nigeria. Eur J Contracept Reprod Health Care. 2005, 10:255-260. Accessed: 


\section{Cureus}

January 21, 2019: 10.1080/13625180500331259

25. Parey B, Addison L, Mark JK, et al.: Knowledge, attitude and practice of emergency contraceptive pills among tertiary level students in Trinidad: a cross-sectional survey. West Indian Med J. 2010, 59:650-655.

26. Hailemariam TG, Tesfaye T, Melese T, et al.: Sexual experiences and emergency contraceptive use among female university students: a cross-sectional study at Wachamo University, Ethiopia. BMC Res Notes. 2015, 8:112. Accessed: November 7, 2018: 10.1186/s13104-015-1070-7

27. Kolawole TOCA, Abubakar M, Zaggi H: Emergency contraceptives use among female students at Ahmadu Bello University, Zaria Kaduna State. TOJNED. 2015, 5:41-48. 